\title{
How Much Insulin Resistance in Polycystic Ovary Syndrome: Comparison of HOMA and Insulin Resistance Index Models.
}

Lewandowski Krzysztof, Łukasiak Katarzyna, Gałuszko Katarzyna, Dukowicz Aleksandra, Cedro Magdalena, Bieńkiewicz Małgorzata, Lewiński Andrzej

Department of Endocrinology \& Metabolic Diseases, The Medical University of Lodz, Poland

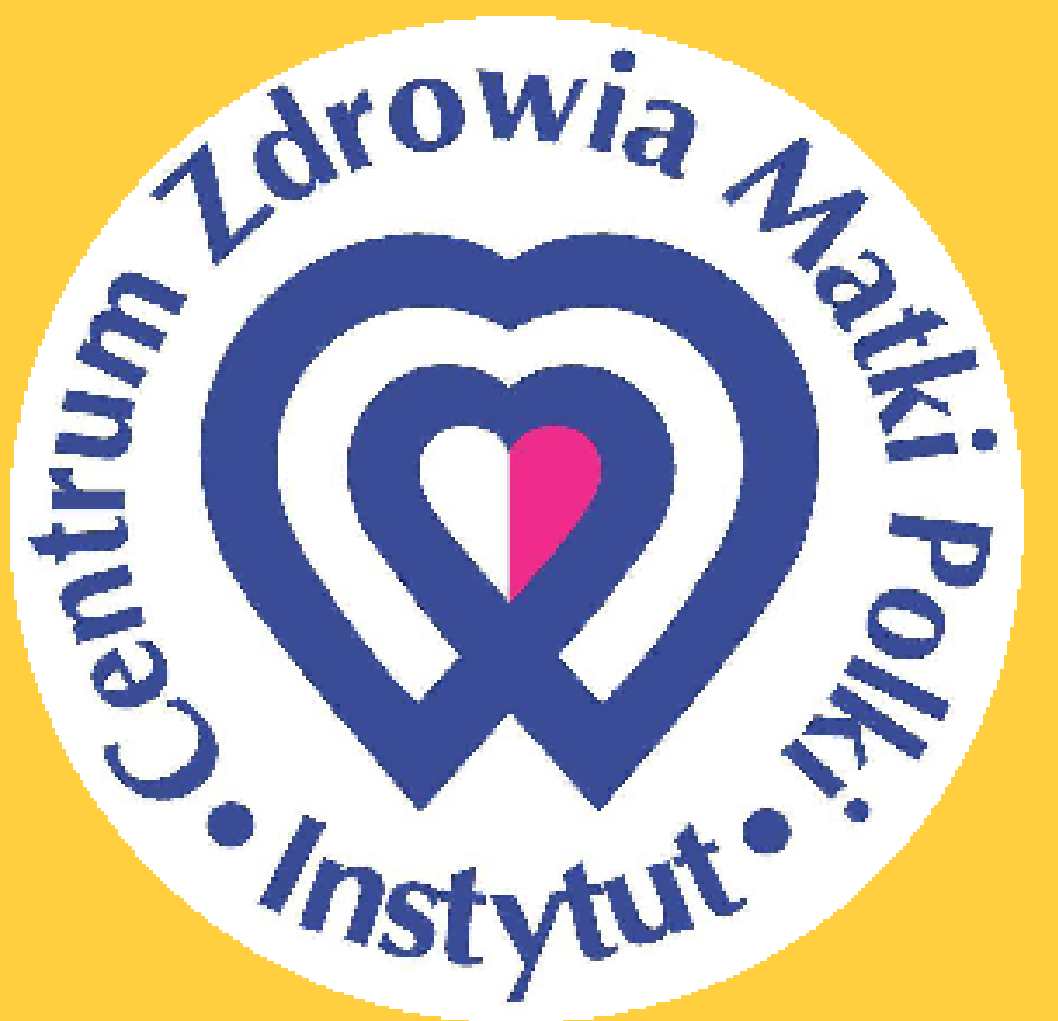

\section{Background}

Polycystic ovary syndrome (PCOS), the commonest endocrinopathy of women in the reproductive age is often accompanied by insulin resistance (IR). The aim of the study was to assess the prevalence of IR in women diagnosed with PCOS, where IR was assessed by methods most commonly used in clinical practice, i.e. homeostatic model assessment (HOMA) and insulin resistance index (IRI), the latter derived from glucose and insulin measurements during oral glucose tolerance test (OGTT)

\section{Patients \& Methods}

The study involved 137 women diagnosed with PCOS according to the Rotterdam criteria (Hum Rep 2004;19:41-47), age (mean \pm SD) 25 \pm 7years, BMI 27.61 \pm 7.43 $\mathrm{kg} / \mathrm{m}^{2}$, investigated in The Department of Endocrinology \& Metabolic Diseases of The Medical University of Lodz, Poland. Insulin resistance was assessed according to the HOMA method [glucose $(\mathrm{mmol} / \mathrm{l})]$ ] [insulin $(\mu \mathrm{U} / \mathrm{ml})$ ]/22.5 (1) and IRI (where $I R$ was diagnosed for $|R|>1.25)(2,3)$. There is no universal agreement as to what HOMA cut-off point should be applied to define insulin resistance. Hence we compared the data using two cut-off points of, i.e. most commonly quoted cut-off point of 3.8 (4) and 3.46, as suggested by Gayoso-Diz et al. (5).

\section{Results}

There was a strongly significant $(p<0.001$ ), but still relatively moderate correlation between IRI and HOMA methods $(r=0.5$ and $r=0.57$ for a linear and non-linear model, respectively) (Figure 1A \& 1B). IR was much more prevalent according to IRI (49.6\%) than according to HOMA $(22.6 \%$ and $15.8 \%$ for 3.46 and 3.8 cutoff points, respectively, $\mathrm{p}<0.01)$. The majority of patients with high HOMA also had high IRI (e.g. $86 \%$, for HOMA $>3.8$ ), but the majority of patients with raised IRI, would not be diagnosed as insulin resistant according to HOMA $(61.7 \%$ and $73.5 \%$, for $\mathrm{HOMA}_{3.46}$ and $\mathrm{HOMA}_{3.80}$, respectively) (Tables 1 \& 2). IRI concentrations were higher among patients with concomitantly raised HOMA $(1.55 \pm 0.18$ vs $1.44 \pm 0.14, p=0.014$, and $1.60 \pm 0.18$ vs $1.44 \pm 0.13, p=0.0008$, for $\mathrm{HOMA}_{3.46}$ and $\mathrm{HOMA}_{3.80}$, respectively, Table 3).

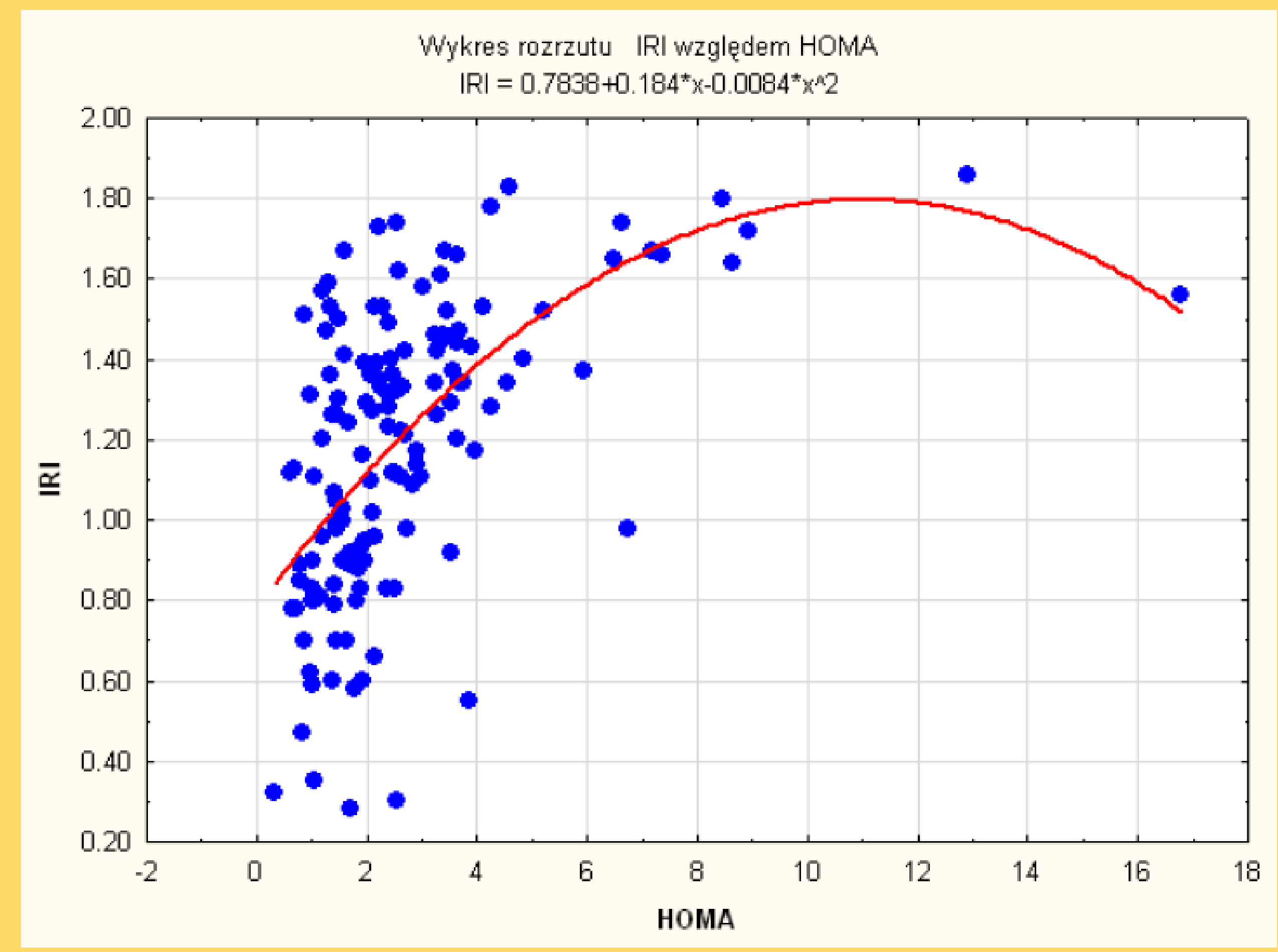

Figure $1 \mathrm{~A}$ : Correlation between IRI and HOMA linear model $(r=0.5, p<0.0001)$

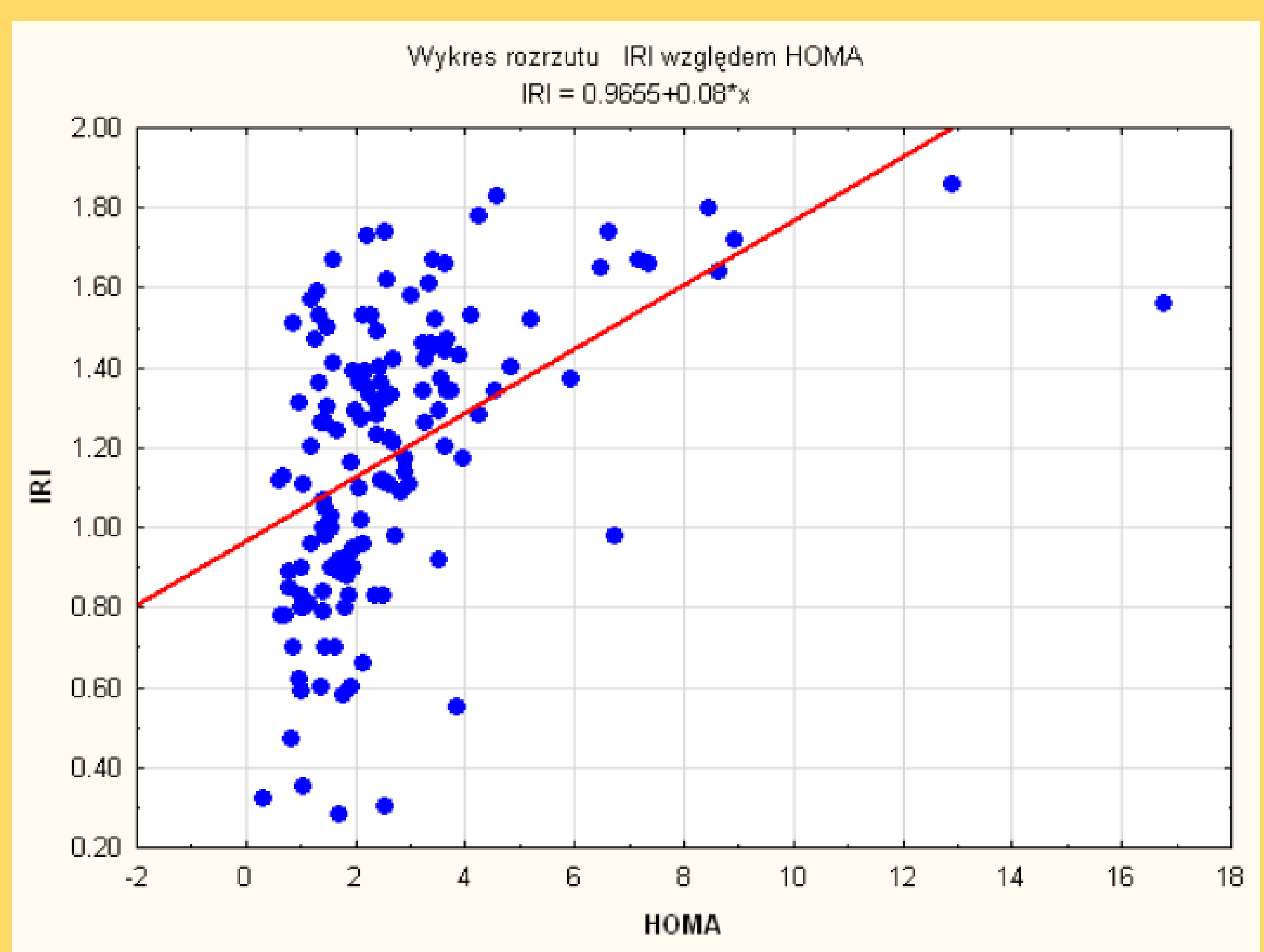

Figure 1 B: Correlation between IRI and HOMA (non-linear model $r=0.57, p<0.001$ )
TABLE 1: Comparison between HOMA and Insulin Resistance Index for assessment of insulin resistance (cut-off for HOMA 3.46). $\mathrm{P}<0.001$ for comparison of distribution of cases with raised IRI versus raised HOMA.

\begin{tabular}{|c|c|c|c|}
\hline \multirow{2}{*}{$|R|_{1.25}$} & \multicolumn{3}{|c|}{ HOMA $_{3.46}$} \\
\hline & $\leq 3.46$ & $>3.46$ & total \\
\hline$\leq 1.25$ & $\begin{array}{c}64 \\
\text { (92.75\% HOMA/IRI concordance } \\
\text { for normal IRI) }\end{array}$ & $\begin{array}{c}5 \\
\text { (7.25\% HOMA/RI discordance } \\
\text { for normal IRI) }\end{array}$ & $\begin{array}{c}69 \\
\text { (50.4\%) }\end{array}$ \\
\hline$>1.25$ & $\begin{array}{c}42 \\
(61.8 \% \text { HOMA/IRI discordance } \\
\text { for raised IRI) }\end{array}$ & $\begin{array}{c}26 \\
(38.2 \% \text { HOMA/IRI concordance } \\
\text { for raised IRI) }\end{array}$ & $\begin{array}{c}68 \\
(49.6 \%)\end{array}$ \\
\hline total & 106 (77.4\%) & 31 (22.6\%) & 137 \\
\hline
\end{tabular}

TABLE 2: Comparison between HOMA and Insulin Resistance Index for assessment of insulin resistance (cut-off for HOMA 3.8). P<0.001 for comparison of distribution of cases with raised IRI versus raised

\begin{tabular}{|c|c|c|c|}
\hline \multirow{2}{*}{$\mid \mathrm{IRI}_{1.25}$} & \multicolumn{3}{|c|}{$\mathrm{HOMA}_{3,80}$} \\
\hline & $\leq 3.80$ & $>3.80$ & total \\
\hline$\leq 1.25$ & $\begin{array}{c}66 \\
(95.7 \% \text { HOMA/IRI concordance } \\
\text { for normal IRI) }\end{array}$ & $\begin{array}{c}3 \\
\text { (4.3\% HOMA/IRI discordance } \\
\text { for normal IRI) }\end{array}$ & $\begin{array}{c}69 \\
(50.4 \%)\end{array}$ \\
\hline$>1.25$ & $\begin{array}{c}50 \\
\text { (73.5\% HOMA/RI discordance } \\
\text { for raised IRI) }\end{array}$ & $\begin{array}{c}18 \\
(26.5 \% \text { HOMA/IRI concordance } \\
\text { for raised IRI) }\end{array}$ & $\begin{array}{c}68 \\
(49.6 \%)\end{array}$ \\
\hline total & $116(84.7)$ & 21 (15.3\%) & 137 \\
\hline
\end{tabular}

TABLE 3: Comparison of Insulin Resistance Index values in women with PCOS with IRI $>1.25$, according to normal and raised HOMA, for HOMA cut-off points of 3.46 and 3.80, respectively.

\begin{tabular}{|l|c|c|c|}
\hline \multicolumn{1}{|c|}{ IRI $>1.25$} & $\mathrm{n}$ & mean \pm st.dev. & p-value \\
\hline HOMA $\leq 3.46$ & 42 & $1.44 \pm 0.14$ & \multirow{2}{*}{0.014} \\
\cline { 1 - 3 } HOMA $>3.46$ & 26 & $1.55 \pm 0.18$ & \multirow{2}{*}{0.0008} \\
\hline HOMA $\leq 3.80$ & 50 & $1.44 \pm 0.13$ & \\
\hline HOMA $>3.80$ & 18 & $1.60 \pm 0.18$ & \\
\hline
\end{tabular}

\section{Discussion \& Conclusions}

Insulin resistance index, based on glucose and insulin measurements during OGTT demonstrates significantly more cases of insulin resistance than HOMA model in women with PCOS. Though there is a significant correlation between both methods of assessment of insulin resistance, overall correlation is rather moderate $\left(R^{\sim 0.5)}\right.$. Therefore detection of insulin resistance among women with PCOS is highly method-dependent and is still more sort of a research tool rather than a method to be applied in standard clinical practice, e.g. while deciding on a use of insulin-sensitizing such as Metformin. It should be noted, however, that with few exceptions, more severe cases of insulin resistance are detected with HOMA rather than with OGTT-related insulin resistance index.

REFERENCES

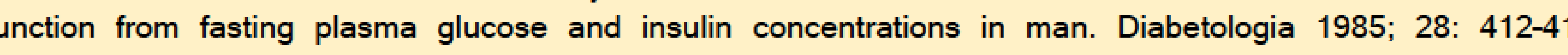
1999; 9: $1462-70$ of individuals who are metabolically healthy obese using different definition criteria. A population-based analysis in the Spanish population. PLoS One. 2014 Sep 8;9(9):e106641. doi: 10.1371 journal.pone.0106641. eCollection 2014 5. Gayoso-Diz P, Olero-Gonzaloz A, Rodnguez-Alvoz MX, Gude F, Garcla F, De Fancisco A, Quintla AG. Insul and age: EPIRCE cross-sectional study. BMC Endor Disord 2013 Oct 16:13:47. 